\title{
Gobernanza de los medios de vida para la adapta- ción al cambio climático en el territorio indígena Amasau, municipio de Waspam, 2017
}

\author{
Livelihood governance for adaptation to climate change in the Amasau indigenous territory, \\ Waspam municipality, 2017
}

\author{
Noe Isaías Lacayo Bushey ${ }^{1}$ \\ Keith Sankara Narváez Ismael²
}

\section{Resumen}

El estudio ha identificado los "medios de vida del territorio Amasau, municipio de Waspam, que están bajo presión del cambio climático", y su relación con el sistema de gobernanza del territorio. La investigación es de tipo cualitativo que asocia una vinculación y comunicación directa entre comunitarios, líderes y representantes del territorio.

El estudio refleja que, la comunidad de Awastingni cuenta con siete principales comunidades, las cuales se fundamentan en los medios de vida de la comunidad. Existe un gran avance de la frontera agrícola provocado por la invasión de colonos que ha causado desequilibrio, por consiguiente, una mala influencia en el uso de los medios de vida. Los grandes retos que tiene este territorio es el defender su territorio ya que los mismos líderes territoriales y comunales junto con autoridades de gobierno y partidos políticos han vendido las tierras comunales. Para enfrentar este proceso, el territorio de Amasau cuenta con cuatro sistemas de gobernanza, que va de la mano para el funcionamiento y desarrollo del territorio.

Palabras clave: Medios de vida; capitales de la comunidad; Cambio climático; gobernanza.

\section{Abstract}

The study has identified the "livelihoods of the Amasau territory, Waspam municipality, which are under pressure from climate change", and their relationship with the territory's governance system. The research is of a qualitative type that associates a direct connection and communication between community members, leaders and representatives of the territory.

The study reflects that the Awastingni community has seven main communities, which are based on the community's livelihoods. There is a great advance in the agricultural frontier caused by the invasion of settlers that has caused an imbalance, therefore, a bad influence on the use of livelihoods. The great challenges that this territory has is defending its territory since the same territorial and communal leaders together with government authorities and political parties have sold the communal lands. To face this process, the Amasau territory has four governance systems, which go hand in hand for the operation and development of the territory.

Keywords: Livelihoods; community capitals; Climate change; governance.

\footnotetext{
1 Ingeniero Agroforestal, (URACCAN). Correo: noeisa23@gmail.com ORCID: https://orcid.org/0000-0003-1187-0370

2 Máster en Planificación y Desarrollo Regional con Identidad, Coordinador Cooperación Externa de la Universidad de las Regiones Autónomas de la Costa Caribe Nicaragüense-Recinto Universitario Bilwi. Correo: Correo: cooperacion.bilwi@uraccan.edu.ni ORCID: https://orcid.org/0000-0003-3268-2643
} 


\section{Introducción}

El cambio climático se posiciona como uno de los problemas que definen nuestra contemporaneidad y, al mismo tiempo, un tema de investigación y el diseño de políticas de desarrollo en el ámbito internacional, nacional, regional y local. Por otro lado, el concepto de gobernanza se ha convertido en un componente importante del discurso de desarrollo, incluye el discurso referente a los bosques y cambio climático. Hasta el momento los marcos políticos y jurídicos nacionales no han logrado hacer frente a la adaptación y mucho menos a la mitigación al cambio climático de forma comprensiva, lo cual incluye estrategias e incentivos a corto, mediano y largo plazo. Sin embargo, el cambio climático ha impactado poblaciones, afecta los procesos de generación de activos y la seguridad de los medios de vida.

En el territorio de Amasau con mucha masa de bosque tropical húmedo y con gran potencial para desarrollar acciones de conservación y captura de carbono, se hace necesario conocer el grado de gobernanza de los recursos naturales y fortalecer sus estructuras con el objetivo de incrementar su capacidad de gestión, empoderamiento y adaptación de actores ante el cambio climático.

La investigación prevé una valoración de las prácticas de gestión comunal a la luz de los nuevos retos que plantea la adaptación al cambio climático. Y que estos retos puedan ser considerados en los planes estratégicos del territorio de Amasau.

\section{Revisión de literatura}

\section{Medios de vida}

Mientras que Ramírez, Hernández, Rivas, Padilla, Ete (2012: P: 19-20) describen al termino medios de vida que comprenden todos los recursos (materiales y humanos) con que cuenta una comunidad (capitales) y todas las actividades que mujeres y hombres realizan usando y cuidando esos recursos.

\section{Capitales de la comunidad}

Ramírez, Hernández, Rivas, Padilla, Ete (2012), plantea que los capitales de una comunidad es el conjunto de todos los recursos (humanos y materiales) con los que contamos hombres y mujeres para lograr una vida digna y feliz. Así también, los desglosan en 7 capitales: capital social, capital cultural, capital político, capital humano, capital natural, capital físico construido, capital financiero productivo.

\section{Territorio}

Huanacuni $(2010,7)$ plantea que territorio no es sólo un espacio geográfico, como piensan los estados. Son recursos naturales, es la frontera, es delimitación, es la estructura, es la organización, es mucha más, porque todo es integral. Ahí se vive y se convive.

\section{Comunidad}

Ley $28,(1987 ; 38)$ establece la comunidad como un conjunto de familias ameri-india que comparten sentimientos de identificación, vinculado a su pasado aborigen y que mantienen rasgos y valores propios de su cultura tradicional, así como formas de tenencias y uso comunal y de organización social propia.

\section{Estructura organizacional}

La estructura organizacional comunitaria se refiere a las formas propias ancestrales que han desarrollado las comunidades para regular los procesos de toma de decisiones basado en el aprovechamiento de sus recursos naturales a nivel interno, Ley 28 (1987). 


\section{La gobernanza}

La gobernanza de los medios de vida es un conjunto de normas, instituciones y procesos que determinan cómo se ejercen el poder y las responsabilidades, cómo se toman las decisiones y cómo los ciudadanos participan en el manejo de los medios de vida. La gobernanza de los medios de vida se ha convertido en un tema fundamental en las discusiones sobre desarrollo sostenible, y está adquiriendo mayor importancia en el proceso de cambio climático (Gonzalo, 2013:2).

\section{Cambio climático}

El IPCC (2002), menciona que el cambio climático es una importante variación estadística del clima que persiste durante un largo período de tiempo, variaciones de carácter identificables, según la nueva explicación del concepto proporcionado por el mismo IPCC (2007).

De acuerdo a Cunningham, et al. (2009), los pueblos indígenas son los que contribuyen en menor proporción a este cambio de clima; sin embargo, con el resto del mundo están en ventaja con la naturaleza por los impactos en sus ecosistemas: Inundaciones masivas, fuertes huracanes, tormentas, destrucción, deslizamiento de tierras, pérdida de aguas frescas, incrementos de microorganismos patógenos y vectores, falta de servicios básicos, entre otros.

\section{Metodología y materiales}

El estudio es cualitativo por lo que está orientado en conocer la percepción del estado de gobernanza de los medios de vida para el cambio climático en el territorio Amasau. El estudio se desarrolló en la comunidad mayangna de Awastingni, territorio indígena de Amasau, del municipio de Waspam, RACCN, Nicaragua. La comunidad está habitada por la etnia Mayagna ubicada en el Municipio de Waspam. Se ubica aproximadamente a $111 \mathrm{Km}$ de la ciudad de Bilwi y a $55 \mathrm{Km}$ de la ciudad de Waspam. Actualmente el territorio cuenta una extensión de 73,394 Ha de bosque, según diagnostico territorial (2003), los cuales son propiedad territorial, tituladas en el año 2008 por el Gobierno central.

De acuerdo al interés de la investigación, se trabajó con cuatros sectores principales para dar salida a la investigación: Lideres y líderesas de la comunidad, productores y productoras, grupos de adultos de la tercera edad y grupo de jóvenes de la comunidad.

\section{Resultado y discusión}

\section{Medios de vida del territorio Amasau que están bajo presión}

Los medios de vida son todos aquellos bienes que puede estar dentro de un área determinada ocupando un espacio y que puede ser aprovechable para uso de ya sea una población o una empresa. Ramírez, Hernández, Rivas y Padilla (2012: P: 19-20).

El territorio indígena Amasau presenta una gran variedad de recursos naturales, debido al grado de conservación practicado por los habitantes del territorio (Grupo Focal jóvenes).

Dentro del territorio se encuentran ubicados los medios de vida, que hacen del mismo un espacio codiciable por ajenos al territorio y la comunidad para practicar la ganadería intensiva y otras actividades no tradicionales a la zona. En el territorio, se encuentran árboles de especies comerciales, zonas mineras ubicado en los cerros, estos todavía no han sido aprovechados, además cuenta con el río Wawa que es un gran recurso para movilización y al mismo tiempo se practica la pesca. 
Pero es una realidad que, en los últimos años, la invasión y el gran avance de colonos dentro del territorio es latente, por ende los medios de vida se encuentran bajo presión, sin tener claro la sostenibilidad y la conservación de la misma.

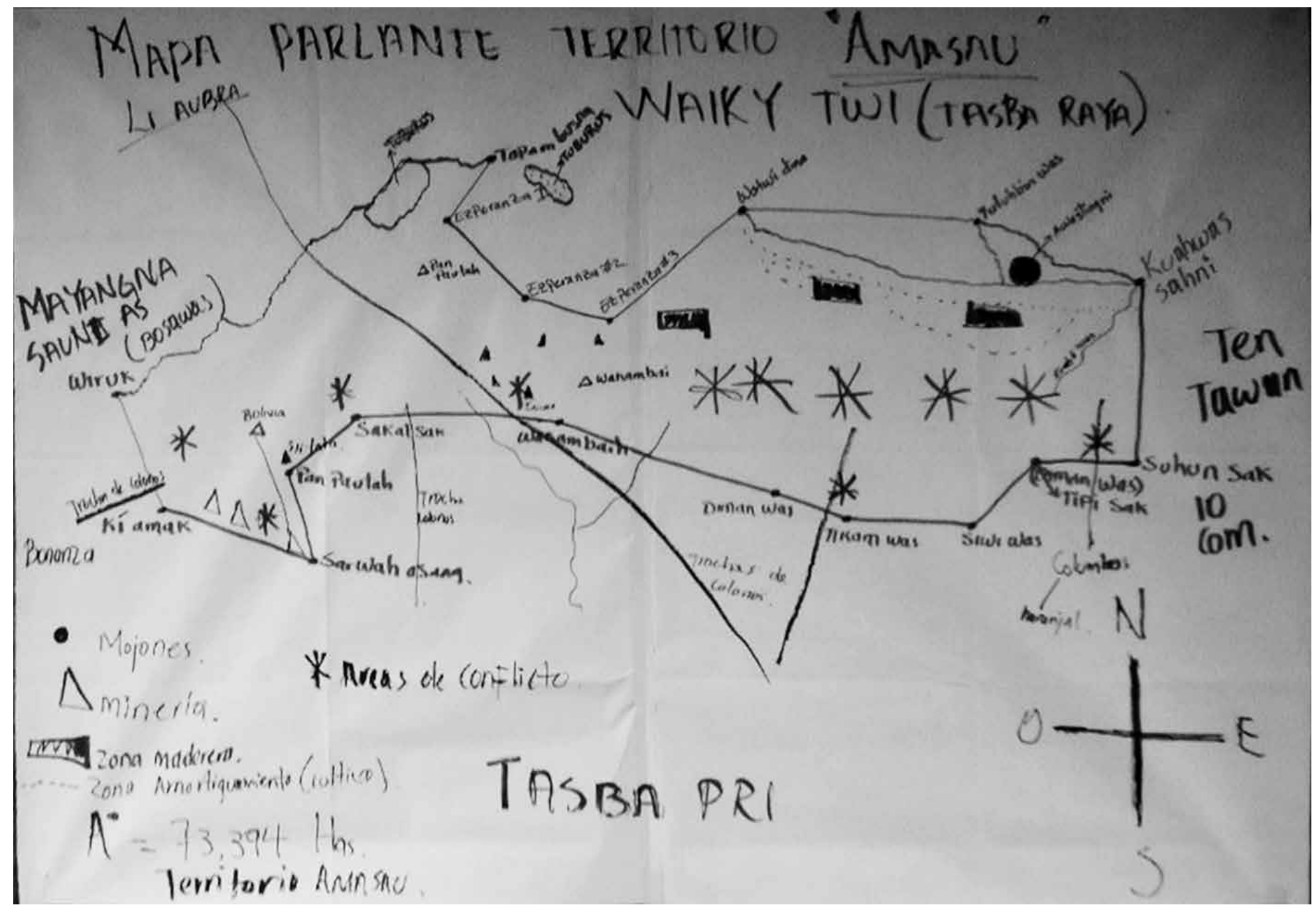

Figura 1. Capitales de la comunidad de Awastingni

En base al mapa parlante, se identificaron los capitales de la comunidad de Awastingni, en relación a los medios de vida con que cuenta el territorio.

Tabla 1. Capitales de la comunidad de Awastingni

\begin{tabular}{|c|l|}
\hline \multicolumn{1}{|c|}{ Capitales } & \multicolumn{1}{c|}{ Capitales de la comunidad } \\
\hline \multirow{4}{*}{ 1- Capital Social } & $\begin{array}{l}\text { - Las escuelas (primaria y secundaria). } \\
\text { - Las iglesias. }\end{array}$ \\
& $\begin{array}{l}\text { - La asamblea comunal y territorial. } \\
\text { - La salud (centro de salud). }\end{array}$ \\
& $\begin{array}{l}\text { Llama la atención, el hecho de que los pastores se consideren como un capital social, por su tra- } \\
\text { bajo en la comunidad y no como un capital político, ya que también participan en resolución de } \\
\text { conflictos en el territorio. Esto se debe a que ésta imagen es concebida como eje fundamental } \\
\text { para el desarrollo y bienestar de una comunidad. }\end{array}$ \\
\hline
\end{tabular}




\begin{tabular}{|c|c|}
\hline Capitales & Capitales de la comunidad \\
\hline 2- Capital Cultural & $\begin{array}{l}\text { - Se conserva los alimentos (wabul, pescado, buña, pozol). } \\
\text { - La conservación del medio ambiente. } \\
\text { - El sistema productivo, rotación de parcela. } \\
\text { - La práctica de la ganadería extensiva. } \\
\text { En este aspecto cabe resaltar que, durante el paso de los años, el cambio del clima viene afec- } \\
\text { tando ya que los ríos ya no tienen la misma cantidad de peces lo que obliga a los comunitarios ir } \\
\text { más lejos para poder realizar la actividad de pesca. }\end{array}$ \\
\hline Capitales & Capitales de la com \\
\hline 3- Capital político & $\begin{array}{l}\text { - El GCI (Gobierno Comunal Indígena). } \\
\text { - El GTI (Gobierno Territorial Indígena). } \\
\text { - La familia. } \\
\text { Es de resaltar este capital, con el que cuenta el territorio como una fortaleza ya que dentro de } \\
\text { la comunidad hay una buena organización; sin embargo, se tiene poco conocimiento en el } \\
\text { tema de adaptación al cambio climático ya que se han realizado capacitaciones sobre temas de } \\
\text { prevención y mitigación, no así directamente la adaptación ante el cambio climático, según lo } \\
\text { afirma un comunitario: } \\
\text { "Aquí nos vienen a dar muchas capacitaciones sobre muchos temas bonitos pero nosotros que- } \\
\text { remos aprender a cómo adaptarnos al cambio de los tiempos, queremos saber las experiencias } \\
\text { de otros lugares". (entrevista a comunitario). }\end{array}$ \\
\hline 4- Capital humano & $\begin{array}{l}\text { - Técnicos agrónomos } \\
\text { - Maestros } \\
\text { - Enfermeras } \\
\text { - Abogados } \\
\text { - Ingenieros agroforestales } \\
\text { - Sociólogos } \\
\text { - Arquitectos } \\
\text { - Contadores } \\
\text { - Administradores de empresas } \\
\text { Es de resaltar que existe un gran capital humano nativo del territorio; sin embargo, se cuenta con } \\
\text { poco apoyo técnico y de acompañamiento en la resolución de conflictos internos y externos que } \\
\text { se presentan en el territorio. }\end{array}$ \\
\hline 5-Capital natural & $\begin{array}{l}\text { - Arboles de alto valor comercial (caoba (Swieteniamacrophylla), santa maría (calophyllum } \\
\text { brasiliense), cedro (CedrelaOdorata), etc). } \\
\text { - Zona minera. } \\
\text { - Plantas medicinales. } \\
\text { - Áreas protegidas con respaldo legal. } \\
\text { - Río Wawa. } \\
\text {...'Los recursos naturales dentro del territorio son utilizados de una manera conservacionista, } \\
\text { de forma racional debido a la cultura ancestral que mantienen aún los habitantes del territorio". } \\
\text { (Grupo focal adultos, 2016). } \\
\text { Sin embargo, con la invasión de colonos dentro del territorio ha venido a causar un desequilibrio } \\
\text { y por consiguiente una mala influencia en el uso de los medios de vida, ya que se ha venido } \\
\text { cambiando el uso del suelo de vocación forestal a las practicas pecuarias, ya que lo que antes era } \\
\text { masa boscosa, ahora lo están convirtiendo en zonas de potreros para ganadería intensiva. }\end{array}$ \\
\hline
\end{tabular}




\begin{tabular}{|c|c|}
\hline Capitales & Capitales de la comunidad \\
\hline $\begin{array}{l}\text { 6- Capital físi- } \\
\text { co-construido }\end{array}$ & $\begin{array}{l}\text { - } 4 \text { iglesias. } \\
\text { - } 2 \text { escuelas. } \\
\text { - } 1 \text { centro de salud. } \\
\text { - } 1 \text { casa comunal. } \\
\text { - } 2 \text { casas pastorales. } \\
\text { - Carretera de una sola vía en buen estado. } \\
\text { Este territorio es uno que cuenta con un fuerte capital físico ya que durante los tiempos se han } \\
\text { logrado la construcción de infraestructuras; sin embargo, por falta de asesoría técnica y segui- } \\
\text { mientos algunos no funcionan como tal. }\end{array}$ \\
\hline $\begin{array}{l}\text { 7- Capital financie- } \\
\text { ro-productivo }\end{array}$ & $\begin{array}{l}\text { - Ganados (bovino, porcino, equino). } \\
\text { - Parcelas de cultivos (semillas). } \\
\text { - } \text { Recursos mineros. } \\
\text { - Con recursos acuáticos. } \\
\text { - Programas de gobierno. } \\
\text { Es de mucha importancia resaltar que Amasau cuenta con recursos potencialmente aprovecha- } \\
\text { bles sin embargo por la invasión de colonos y por la falta implementación de acciones de apro- } \\
\text { vechamiento, estos se van deteriorando por el cambio climático y no se aprovechan para bien } \\
\text { del territorio. }\end{array}$ \\
\hline
\end{tabular}

En este caso, se lograron identificar 7 capitales que tiene el territorio, dentro de estos capitales mencionados, el capital natural tiene una mayor influencia con respecto a la presión del cambio climático, ya que este medio de vida se encuentra dentro del área protegida del territorio.

En relación con estos capitales, uno de los capitales que señal los comunitarios y que reflejan gran preocupación por su estado, es el capital natural.

Los habitantes del territorio indígena Amasau, desempeñan un papel fundamental en la voluntad de conservar los recursos del medio ambiente y el desarrollo debido a sus conocimientos y prácticas tradicionales (Grupo focal Adultos).

En contraste con esta intervención, otro comunitario confirma que:

Muchos de los comunitarios que poseen grandes cantidades de tierras, las han vendido a colonos y esta no es una forma de conservar el medio ambiente (Grupo focal Adultos).

Por lo que todos consensuan la idea de que se necesita un apoyo de parte de las instituciones del estado, para frenar el avance de la frontera agrícola, afirman dos comunitarios:

Las mismas autoridades del gobierno son los que otorgan aval de uso de suelo a colonos (Grupo focal jóvenes).

Se debe tomar medidas aun con los mismos líderes territoriales y comunales ya que ellos mismos junto con las autoridades del gobierno y consejo regional se han encargado de vender nuestras tierras (Grupo focal Adultos).

En base a estos resultados podemos decir que, el territorio indígena Amasau, es un territorio que cuenta con gran potencial de recursos. Sin embargo por la debilidad institucional, se han prestado a la negociación y venta de sus propias tierras en conjunto con las autoridades del gobierno y dirigentes de 
partidos políticos, hacen que hoy en día este territorio este al borde de convertirse en una área desolada y con único fin de uso para potreros (ganadería) provocando así la represión en pocos espacios a una etnia entera como es la etnia mayangna, reduciéndolos a vivir en espacios pequeños donde no pueden realizar sus actividades de conservación en base a costumbres ancestrales.

\section{Sistema de gobernanza del territorio Amasau para sus medios de vida}

La gobernanza se concibe como el conjunto de normas, instituciones y procesos que determinan cómo se ejercen el poder y las responsabilidades, cómo se toman las decisiones y cómo los ciudadanos participan en el manejo de los recursos naturales (Gonzalo, 2013:2). En el caso del territorio de Amasau se ha logrado identificar estos sistemas e instrumentos de gobernanza para sus medios de vida.

\section{Marco normativo}

Es de mencionar que las normas responden a las necesidades del Estado, gobierno y sociedades, y a las corrientes ambientalistas que inundan el ámbito de la opinión pública, a fin de tener un control sobre el uso de los recursos. En este sentido, los habitantes del territorio indígena Amasau, expresan que al pasar del tiempo se ha tratado de regular el acceso, uso, control y protección de sus medios de vida.

Los recursos con los que tiene el territorio son regulados por normas y costumbres ancestrales que controlan su uso, pero hoy ya no se respetan esas normas, por ejemplo, hay lugares donde antes era prohibido ir de cacería porque son áreas protegidas, pero hoy ya no se respeta eso, porque no se han respetado las reglas que conservan nuestros recursos, antes había un área solo para casería, otro para pesca y otros para aprovechar la madera, pero hoy ya no se realizan esas prácticas ancestrales.(Entrevista N.2).

Otra práctica, es la distribución de lotes de tierra por familia:

Con relación a las normas que existen para hacer uso de los recursos naturales que se encuentran dentro del territorio, cada familia tiene su espacio donde trabajar sus parcelas, las tierras aquí son del territorio y por eso para aprovechar los recursos se debe tener a mano un aval de parte del territorio, además se debe pagar un impuesto por tronco naje (madera en rollo) a la comunidad. (EntrevistaN.2).

\section{La institucionalidad del territorio}

Las autoridades comunales y territoriales han recibido poderes jurídicos en lo que respecta a la gobernanza de sus recursos naturales. Esta articulación abarca una serie de oportunidades para prosperar con el funcionamiento de una institucionalidad tradicional fundamentada en una gestión colectiva, basada en las normas ancestrales.

En cuanto a quien es la estructura organizacional que confirma la institucionalidad indígena, surge una discusión y se difieren entre ellas.

la estructura que confirma la institución indígena es el gobierno, porque ellos son los que dan el aval a las autoridades electas (Comunitario de Awastingni 1).

el pueblo es quien confirma la institución, ya que para que haya una institución se necesitan de participantes estos jóvenes (Comunitario de Awastingni 2).

la estructura que confirma es el GTI, que está sobre la comunidad (Comunitario de Awastingni 3). 
De acuerdo con el Convenio de la OIT en su artículo 18 establece que los pueblos indígenas tienen derecho a participar en la adopción de decisiones en las cuestiones que afecten sus derechos, por conducto de representantes elegidos por ellos de conformidad con sus propios procedimientos, así como a mantener y desarrollar sus propias instituciones de adopción de decisiones. (pág. 33).

Por lo que podemos compartir la idea de que el pueblo es el actor clave en la confirmación de la institucionalidad indígena, las cuales son representadas por su líder territorial, como canalizador de las demandas de su pueblo. Pero, de acuerdo con esta dinámica estructural institucional actual hay un rompimiento "drástico y significativo" al conocimiento de los canales y las responsabilidades que deben de asumir cada estructura en sus niveles de gobernanza tradicional y reconocidas por las leyes nacionales e internacional.

\section{Resolución de conflictos internos}

El territorio Amasau, como cualquier otro territorio enfrenta conflictos internos con relación a la gestión de los medios de vida, entre otros. En este sentido, el territorio cuenta con un "Diagnóstico de tenencia y uso de la tierra de la comunidad de Awastingni" y el manual del territorio, ambos validados en 2003, que fue elaborado con el fin de tener un método escrito que sirva de generación a generación, para la resolución de conflictos interno dentro de la comunidad:

Un comunitario plantea que, "los conflictos se resuelven mediante el uso del manual del territorio que se creó para usarse cuando hay conflictos dentro de la comunidad que tenga que ver con recursos, pleitos de familia y otros más (entrevista N.2)". Cabe mencionar los encargados de resolver conflictos internos, según lo referido por este comunitario:

Los conflictos dentro de la comunidad se resuelven por medio de las autoridades de la comunidad como el wihta, existen sanciones que se aplican (entrevista. 2).

\section{Proceso de toma de decisión}

Dentro del territorio existen actores claves el proceso de toma de decisiones, a fin de encaminar al territorio hacia una ruta de desarrollo de sus capitales comunitarias.

Plantea Saavedra (2007), en este sentido vale hacer énfasis que uno de los ejes centrales de la gestión comunitaria es que, las comunidades sean capaces de administrar, operar y mantener los sistemas con criterios de eficiencia, eficacia y equidad tanto social como de género. Estos entes comunales, toman todas las decisiones, teniendo el control de los recursos (técnicos, financieros, de personal, entre otros,) y establecen relaciones horizontales con servicios gubernamentales y no gubernamentales que apoyan su gestión

Sin embargo, dentro del territorio existen algunas inconformidades con relación al tema de la mujer en el proceso de participación y toma de decisión dentro del territorio, ya que poco se toma en cuenta su opinión, según lo afirma el comunitario:

Las mujeres y los jóvenes muy pocas veces son tomados en cuenta, siempre se deciden entre los hombres, igual, las mujeres son vistas como trabajadoras de casa (entrevista N. 2).

Sin embargo, tomando en cuenta la opinión de otro comunitario, quien afirma que sí se toma en cuenta a la mujer:

Muchas mujeres son menospreciadas por ser mujeres y por ser jóvenes, pero en el territorio cuando se realizan las asambleas, se convoca a todo el pueblo y las mujeres y jóvenes igual, participan y se les toma en cuenta con respeto (entrevista N. 2). 
Mairena, (2012) explica que la participación de las mujeres en la gestión de los medios de vida se observa en la obtención de leña del bosque, mientras que son los hombres los que talan, venden árboles y madera a actores externos y toman las decisiones.

Sin embargo, dentro de Amasau se ha venido poniendo en práctica la equidad de género. Por lo tanto, Podemos decir que como territorio hay un grado de respeto hacia la mujer y se le concede valor dentro de las asambleas comunales y territoriales.

Tabla 2. Sistema de gobernanza vs capitales de la comunidad

\begin{tabular}{|c|c|c|c|c|c|c|}
\hline \multirow[b]{2}{*}{ Capitales } & \multirow[b]{2}{*}{ Capitales de la comunidad } & \multicolumn{4}{|c|}{ Sistema de gobernanza } & \multirow[b]{2}{*}{ Total } \\
\hline & & $\begin{array}{c}\text { Marco } \\
\text { Normativo }\end{array}$ & $\begin{array}{l}\text { La institucionalidad del } \\
\text { territorio }\end{array}$ & $\begin{array}{l}\text { Resolución } \\
\text { de conflictos } \\
\text { internos }\end{array}$ & $\begin{array}{c}\text { Proceso de } \\
\text { toma de } \\
\text { decisión }\end{array}$ & \\
\hline $\begin{array}{l}\text { 1- Capital } \\
\text { Social }\end{array}$ & $\begin{array}{l}\text { - Las escuelas (primaria y secundaria). } \\
\text { - Las iglesias. } \\
\text { - La asamblea comunal y territorial. } \\
\text { - La salud (centro de salud). } \\
\text { - Convenio con las universidades (URACCAN y } \\
\text { BICU) Y otras instituciones. } \\
\text { - Los pastores y maestros. }\end{array}$ & 2 & 3 & 1 & 2 & 8 \\
\hline $\begin{array}{l}\text { 2-Capital } \\
\text { Cultural }\end{array}$ & $\begin{array}{l}\text { - Se conserva los alimentos (wabul, pescado, } \\
\text { buña, pozol molido en piedras de moler). } \\
\text { - La conservación del medio ambiente. } \\
\text { - El sistema productivo, rotación de cultivo. } \\
\text { - La práctica de la ganadería extensiva. }\end{array}$ & 3 & 2 & 1 & 1 & 7 \\
\hline $\begin{array}{l}\text { 3- Capital } \\
\text { político }\end{array}$ & $\begin{array}{l}\text { - El GCI (Gobierno Comunal Indígena). } \\
\text { - El GTI (Gobierno Territorial Indígena). } \\
\text { - El síndico y wihta. } \\
\text { - El consejo de ancianos. } \\
\text { - La familia. } \\
\text { - Las organizaciones comunitarias encargadas } \\
\text { de guardar el bosque. }\end{array}$ & 3 & 3 & 3 & 3 & 12 \\
\hline $\begin{array}{l}\text { 4-Capital } \\
\text { humano }\end{array}$ & $\begin{array}{l}\text { - Técnicos agrónomos. } \\
\text { - Maestros. } \\
\text { - Enfermeras. } \\
\text { - Abogados. } \\
\text { - Ingenieros agroforestales. } \\
\text { - Sociólogos. } \\
\text { - Arquitectos. } \\
\text { - Contadores. } \\
\text { - Administradores de empresas. }\end{array}$ & 1 & 1 & 1 & 1 & 4 \\
\hline $\begin{array}{l}\text { 5-Capital } \\
\text { natural }\end{array}$ & $\begin{array}{l}\text { - Arboles de alto valor comercial Caoba } \\
\text { (Swieteniamacrophylla), santa maría (calophy- } \\
\text { llum brasiliense), cedro (CedrelaOdorata), etc). } \\
\text { - Zona minera. } \\
\text { - Plantas medicinales. } \\
\text { - Áreas protegidas con respaldo legal. } \\
\text { - Río Wawa. }\end{array}$ & 3 & 3 & 3 & 3 & 12 \\
\hline
\end{tabular}




\begin{tabular}{|c|c|c|c|c|c|c|}
\hline \multirow[b]{2}{*}{ Capitales } & \multirow[b]{2}{*}{ Capitales de la comunidad } & \multicolumn{4}{|c|}{ Sistema de gobernanza } & \multirow[b]{2}{*}{ Tota } \\
\hline & & $\begin{array}{c}\text { Marco } \\
\text { Normativo }\end{array}$ & $\begin{array}{l}\text { La institucionalidad del } \\
\text { territorio }\end{array}$ & $\begin{array}{l}\text { Resolución } \\
\text { de conflictos } \\
\text { internos }\end{array}$ & $\begin{array}{l}\text { Proceso de } \\
\text { toma de } \\
\text { decisión }\end{array}$ & \\
\hline $\begin{array}{l}\text { 6- Capital } \\
\text { físico-cons- } \\
\text { truido }\end{array}$ & $\begin{array}{l}\text { - Cuatro iglesias. } \\
\text { - } 2 \text { escuelas. } \\
\text { - } 1 \text { centro de salud. } \\
\text { - } 1 \text { casa comunal. } \\
\text { - } 2 \text { casas pastorales. } \\
\text { - } \text { Una carretera en buen estado. }\end{array}$ & 3 & 2 & 3 & 2 & 10 \\
\hline \multirow[t]{2}{*}{$\begin{array}{l}\text { 7- Capital } \\
\text { financie- } \\
\text { ro-produc- } \\
\text { tivo }\end{array}$} & $\begin{array}{l}\text { - Ganados (bovino, porcino, equino). } \\
\text { - Parcelas de cultivos (semillas). } \\
\text { - Recursos mineros. } \\
\text { - Los recursos acuáticos. } \\
\text { - Conocimientos básicos de elaboración de } \\
\text { botes. } \\
\text { - Programas de gobierno. }\end{array}$ & 3 & 2 & 3 & 3 & 11 \\
\hline & & 18 & 16 & 15 & 15 & 64 \\
\hline
\end{tabular}

Nota: 1 Sistema de gobernanza de incidencia Nula al Capital 2 Sistema de gobernanza de incidencia Media al Capital 3 Sistema de gobernanza de incidencia Alta al Capital

En la tabla 2 se puede observar que dentro de los sistemas de gobernanza que se pudieron identificar dentro del territorio Amasau, el marco normativo es el que tiene mayor incidencia a los capitales de la comunidad, esto se debe a que dentro del territorio existe una organización por sectores, los cuales rigen en todas las áreas tales como uso, control y acceso a los medios de vida con los que cuenta el territorio. De igual manera llama la atención que dentro de este sistema de gobernanza, se pongan en práctica las costumbres ancestrales.

En el caso de los capitales, el capital natural presenta mayor incidencia de los sistemas de gobernanza del territorio, ya que este capital representa el área donde se ejerce presión sobre los medios de vida los cuales abarcan, las áreas de minería, áreas protegidas entre otras. En el caso del capital que no demanda de manera significativa la incidencia del sistema de gobernanza es el capital humano, ya que el territorio cuenta con una gran cantidad de recursos humanos profesionales, sin embargo, estos en su mayoría no residen dentro del territorio por lo que no tienen influencia directa dentro de las asambleas comunales y territoriales para la toma de decisiones a fin de encaminar hacia una línea de desarrollo al territorio.

\section{Líneas de acción de adaptación al cambio climático basadas a los medios de vida en el territorio Amasau}

El IPCC (2002), menciona que el cambio climático es una importante variación estadística del clima que persiste durante un largo período de tiempo, variaciones de carácter identificables, según la nueva explicación del concepto proporcionado por el mismo.

De acuerdo con Cunningham, et (2009), los pueblos indígenas son los que afectan en menor proporción a este cambio de clima; sin embargo, comparten con el resto del mundo, pero en gran desventaja los impactos en sus ecosistemas: Inundaciones masivas, fuertes huracanes, tormentas, destrucción, deslizamiento de tierras, pérdida de aguas frescas, incrementos de microorganismos patógenos y vectores, falta de servicios básicos, entre otros. 
Todo esto puede producir impactos de aislamiento e inseguridad alimentaria en las comunidades indígenas y afro descendientes, quebrantando la vida cultural y por ende causando la pérdida de conocimientos tradicionales y en un aumento de la presión social y cultural por los impactos adversos a su medio de vida.

El territorio posee sus fortalezas, oportunidades, debilidades y amenazas, que fueron expuestas por comunitarios, siendo estas las que se presentan en la tabla 3.

Tabla 3. FODA del territorio de Amasau, para sus medios de vida.

\begin{tabular}{|c|c|}
\hline FORTALEZAS (Interna) & OPORTUNIDADES (Externa) \\
\hline $\begin{array}{l}\text { - El territorio cuenta con una oficina equipa- } \\
\text { da con equipos tecnológicos: computadora, } \\
\text { impresora, GPS, radio de comunicación, } \\
\text { panel solar. } \\
\text { - Dentro del territorio hay educación primaria } \\
\text { y secundaria. } \\
\text { - Cuenta con un manual de saneamiento. } \\
\text { - Título de propiedad. } \\
\text { - Hay representación del territorio a nivel } \\
\text { - nacional. } \\
\text { Vía de acceso terrestre. }\end{array}$ & $\begin{array}{l}\text { - Convenios con las dos universidades de la región. } \\
\text { - Se cuenta con asesoría técnica de algunas instituciones } \\
\text { en temas de interés del territorio. } \\
\text { - Hay representación en el consejo municipal. } \\
\text { - El vice canciller de la república, nativo del territorio. } \\
\text { - Oficina de "Nación Mayangna" } \\
\text { - Contactos con el gobierno regional y consejo regional. } \\
\text { - Se cuenta con el apoyo de la policía en tema de seguri- } \\
\text { dad y resolución de conflictos internos. } \\
\text { - Existe una comisión guarda bosques. }\end{array}$ \\
\hline DEBILIDADES (Interna) & AMENAZA (Externa) \\
\hline $\begin{array}{l}\text { - Falta de coordinación con instancias supe- } \\
\text { riores. } \\
\text { - Falta de plazas fijas para docentes. } \\
\text { - Falta de personal médico para atender di- } \\
\text { rectamente las necesidades médicas dentro } \\
\text { del territorio. } \\
\text { - Falta de autoridad en la familia, de los pa- } \\
\text { dres hacia los hijos. }\end{array}$ & $\begin{array}{l}\text { - Invasión de colonos dentro del territorio. } \\
\text { - Influencia de partidos políticos en la toma de decisiones } \\
\text { dentro del territorio. } \\
\text { - Apropiación de informaciones importantes del territorio } \\
\text { en mano de instituciones. } \\
\text { - Otorgamiento de documentos de uso de propiedad den- } \\
\text { tro del territorio a colonos por parte de autoridades del } \\
\text { estado. } \\
\text { - Avance de la frontera agrícola. } \\
\text { - El cambio climático. } \\
\text { - Tala de los bosques en áreas protegidas dentro del territo- } \\
\text { rio. }\end{array}$ \\
\hline
\end{tabular}

El territorio Amasau está caracterizado por gozar de los patrimonios de sus medios de vida, en los cuales los comunitarios juegan papeles importantes como dueños de las tierras, más sin embargo también son identificados por la amplia gama de problemáticas que surgen de manera interna dentro de las comunidades con relación al cambio climático, según lo afirma un comunitario:

Estas son nuestras tierras, todo lo que está dentro de este territorio es de nosotros pero nosotros mismos nos hemos creado problemas por negociar nuestras tierras y eso provoca el cambio climático en el territorio (Entrevista n.1).

El territorio Amasau es uno de los territorios a nivel de la región con gran conocimiento teórico sobre cambio climático por lo que se necesita dar un poco de seguimiento para hacer de este un modelo de vida para otros territorios que aún no poseen estos conocimientos. 
En base a este análisis realizado, con la ayuda de los comunitarios y con experiencias propias, surge las acciones que como territorio deben tener en cuenta, tres etapas: a corto, mediano y largo plazo, a fin de adaptarse al cambio climático que día a día se convierte en un reto para los pueblos indígenas.

En la siguiente tabla se detalla la línea de tiempo de acciones de adaptación al Cambio Climático, en base a los medios de vida que propone el estudio.

Tabla 4. Línea de tiempo de acciones de adaptación al Cambio Climático, en base a los medios de vida que propone el estudio

\begin{tabular}{|c|c|c|c|c|c|c|c|}
\hline \multirow{2}{*}{ Capitales } & \multirow{2}{*}{ Capitales de la comunidad } & \multirow{2}{*}{$\begin{array}{c}\text { Sistema de } \\
\text { gobernanza de } \\
\text { prioridad al capital }\end{array}$} & \multirow{2}{*}{ Oportunidades } & \multirow{2}{*}{ Fortaleza } & \multicolumn{3}{|c|}{ Línea de tiempo (Acciones) } \\
\hline & & & & & Corto (1-5años) & Mediano (6-10) & Largo (11-15) \\
\hline $\begin{array}{l}\text { 1- Capital } \\
\text { Social }\end{array}$ & $\begin{array}{l}\text { - Las escuelas } \\
\text { (primaria y } \\
\text { secundaria) } \\
\text { - Las iglesias } \\
\text { - La asamblea } \\
\text { comunal y terri- } \\
\text { torial } \\
\text { - La salud (centro } \\
\text { de salud) } \\
\text { - Convenio con } \\
\text { las universida- } \\
\text { des (URACCAN } \\
\text { Y BICU) Y otras } \\
\text { instituciones. } \\
\text { - Los pastores y } \\
\text { maestros. }\end{array}$ & $\begin{array}{l}\text { La institucio- } \\
\text { nalidad del } \\
\text { territorio }\end{array}$ & $\begin{array}{l}\text { Se cuenta con } \\
\text { asesoría técni- } \\
\text { ca de algunas } \\
\text { instituciones en } \\
\text { temas de interés } \\
\text { del territorio. } \\
\text { Convenios con las } \\
\text { dos universidades } \\
\text { de la región. }\end{array}$ & $\begin{array}{l}\text { Dentro } \\
\text { del te- } \\
\text { rritorio } \\
\text { hay edu- } \\
\text { cación } \\
\text { primaria y } \\
\text { secunda- } \\
\text { ria. }\end{array}$ & $\begin{array}{l}\text { Instruir a } \\
\text { los niños y } \\
\text { adolescen- } \\
\text { tes en tema } \\
\text { de conser- } \\
\text { vación del } \\
\text { medio am- } \\
\text { biente. }\end{array}$ & $\begin{array}{l}\text { Promover } \\
\text { la práctica } \\
\text { de rotación } \\
\text { de cultivos } \\
\text { en parce- } \\
\text { las. }\end{array}$ & $\begin{array}{l}\text { Administrar nues- } \\
\text { tros medios de } \\
\text { vida sin influencia } \\
\text { de terceros. }\end{array}$ \\
\hline
\end{tabular}




\begin{tabular}{|c|c|c|c|c|c|c|c|}
\hline \multirow{2}{*}{ Capitales } & \multirow{2}{*}{ Capitales de la comunidad } & \multirow{2}{*}{$\begin{array}{c}\text { Sistema de } \\
\text { gobernanza de } \\
\text { prioridad al capital }\end{array}$} & \multirow{2}{*}{ Oportunidades } & \multirow{2}{*}{ Fortaleza } & \multicolumn{3}{|c|}{ Línea de tiempo (Acciones) } \\
\hline & & & & & Corto (1-5años) & Mediano (6-10) & Largo (11-15) \\
\hline $\begin{array}{l}\text { 2- Capital } \\
\text { Cultural }\end{array}$ & $\begin{array}{l}\text { Se conserva los } \\
\text { alimentos (wabul, } \\
\text { pescado, buña, } \\
\text { pozol molido en } \\
\text { piedras de moler) } \\
\text { La conservación } \\
\text { del medio ambien- } \\
\text { te. } \\
\text { El sistema produc- } \\
\text { tivo, rotación de } \\
\text { cultivo. } \\
\text { - La práctica de la } \\
\text { ganadería exten- } \\
\text { siva }\end{array}$ & $\begin{array}{l}\text { Marco norma- } \\
\text { tivo }\end{array}$ & $\begin{array}{l}\text { Existe una co- } \\
\text { misión guarda } \\
\text { bosques. }\end{array}$ & $\begin{array}{l}\text { Vía de } \\
\text { acceso } \\
\text { terrestre. }\end{array}$ & $\begin{array}{l}\text { Conservar el } \\
\text { buen uso de } \\
\text { los medio } \\
\text { de vida, usar } \\
\text { el bosque } \\
\text { de manera } \\
\text { racional. } \\
\text { Delimitar } \\
\text { las áreas de } \\
\text { trabajo en el } \\
\text { bosque. } \\
\text { Instruir a } \\
\text { los niños y } \\
\text { adolescen- } \\
\text { tes en tema } \\
\text { de conser- } \\
\text { vación del } \\
\text { medio am- } \\
\text { biente. }\end{array}$ & $\begin{array}{l}\text { Establecer } \\
\text { leyes den- } \\
\text { tro del te- } \\
\text { rritorio en } \\
\text { marcadas a } \\
\text { conservar } \\
\text { el uso del } \\
\text { bosque. } \\
\text { Frenar la } \\
\text { creación } \\
\text { de potreros } \\
\text { para gana- } \\
\text { do. } \\
\text { Promover } \\
\text { la práctica } \\
\text { de rotación } \\
\text { de cultivos } \\
\text { en parce- } \\
\text { las. }\end{array}$ & $\begin{array}{l}\text { Darle uso racio- } \\
\text { nal a las reservas } \\
\text { mineras. } \\
\text { Administrar nues- } \\
\text { tros medios de } \\
\text { vida sin influencia } \\
\text { de terceros. }\end{array}$ \\
\hline
\end{tabular}




\begin{tabular}{|c|c|c|c|c|c|c|c|}
\hline \multirow{2}{*}{ Capitales } & \multirow{2}{*}{ Capitales de la comunidad } & \multirow{2}{*}{$\begin{array}{c}\text { Sistema de } \\
\text { gobernanza de } \\
\text { prioridad al capital }\end{array}$} & \multirow{2}{*}{ Oportunidades } & \multirow{2}{*}{ Fortaleza } & \multicolumn{3}{|c|}{ Línea de tiempo (Acciones) } \\
\hline & & & & & Corto (1-5años) & Mediano (6-10) & Largo (11-15) \\
\hline $\begin{array}{l}\text { 3- Capital } \\
\text { político } \\
\text { proceso }\end{array}$ & $\begin{array}{l}\text { El GCI (Gobierno } \\
\text { Comunal Indígena). } \\
\text { El GTI (Gobierno } \\
\text { Territorial } \\
\text { Indígena). } \\
\text { El síndico y wihta. } \\
\text { El consejo de an- } \\
\text { cianos. } \\
\text { La familia. } \\
\text { Las organizaciones } \\
\text { comunitarias en- } \\
\text { cargadas de guar- } \\
\text { dar el bosque. }\end{array}$ & $\begin{array}{l}\text { Resolución } \\
\text { de conflictos } \\
\text { y de toma de } \\
\text { decisión. (ni- } \\
\text { vel alto). }\end{array}$ & $\begin{array}{l}\text { Se cuenta con el } \\
\text { apoyo de la po- } \\
\text { licía en tema de } \\
\text { seguridad y reso- } \\
\text { lución de conflic- } \\
\text { tos internos. }\end{array}$ & $\begin{array}{l}\text { Dentro } \\
\text { del te- } \\
\text { rritorio } \\
\text { hay edu- } \\
\text { cación } \\
\text { primaria y } \\
\text { secunda- } \\
\text { ria. } \\
\text { Cuenta } \\
\text { con un } \\
\text { manual } \\
\text { de sanea- } \\
\text { miento. } \\
\text { Título de } \\
\text { propie- } \\
\text { dad. } \\
\text { Hay re- } \\
\text { presenta- } \\
\text { ción del } \\
\text { territorio } \\
\text { a nivel } \\
\text { nacional. }\end{array}$ & $\begin{array}{l}\text { Buscar } \\
\text { proyectos } \\
\text { de refores- } \\
\text { tación, refo- } \\
\text { restar áreas } \\
\text { despaladas. }\end{array}$ & $\begin{array}{l}\text { Establecer } \\
\text { leyes den- } \\
\text { tro del te- } \\
\text { rritorio en } \\
\text { marcadas a } \\
\text { conservar } \\
\text { el uso del } \\
\text { bosque. }\end{array}$ & $\begin{array}{l}\text { Administrar nues- } \\
\text { tros medios de } \\
\text { vida sin influencia } \\
\text { de terceros. }\end{array}$ \\
\hline
\end{tabular}




\begin{tabular}{|c|c|c|c|c|c|c|c|}
\hline \multirow{2}{*}{ Capitales } & \multirow{2}{*}{ Capitales de la comunidad } & \multirow{2}{*}{$\begin{array}{c}\text { Sistema de } \\
\text { gobernanza de } \\
\text { prioridad al capital }\end{array}$} & \multirow{2}{*}{ Oportunidades } & \multirow{2}{*}{ Fortaleza } & \multicolumn{3}{|c|}{ Línea de tiempo (Acciones) } \\
\hline & & & & & Corto (1-5años) & Mediano (6-10) & Largo (11-15) \\
\hline $\begin{array}{l}\text { 4- Capital } \\
\text { humano }\end{array}$ & $\begin{array}{l}\text { Técnicos agróno- } \\
\text { mos. } \\
\text { Maestros. } \\
\text { Enfermeras. } \\
\text { Abogados. } \\
\text { Ingenieros agrofo- } \\
\text { restales. } \\
\text { Sociólogos. } \\
\text { Arquitectos. } \\
\text { Contadores. } \\
\text { Administradores de } \\
\text { empresas. }\end{array}$ & $\begin{array}{l}\text { Marco nor- } \\
\text { mativo, } \\
\text { Resolución de } \\
\text { conflictos, La } \\
\text { institucionali- } \\
\text { dad del terri- } \\
\text { torio, proceso } \\
\text { de toma de } \\
\text { decisión. (ni- } \\
\text { vel bajo). }\end{array}$ & $\begin{array}{l}\text { Se cuenta con } \\
\text { asesoría técni- } \\
\text { ca de algunas } \\
\text { instituciones en } \\
\text { temas de interés } \\
\text { del territorio. } \\
\text { Hay representa- } \\
\text { ción en el consejo } \\
\text { municipal. } \\
\text { El vice canciller de } \\
\text { la república, nati- } \\
\text { vo del territorio. }\end{array}$ & $\begin{array}{l}\text { Hay re- } \\
\text { presenta- } \\
\text { ción del } \\
\text { territorio } \\
\text { a nivel } \\
\text { nacional. }\end{array}$ & $\begin{array}{l}\text { Instruir a } \\
\text { los niños y } \\
\text { adolescen- } \\
\text { tes en tema } \\
\text { de conser- } \\
\text { vación del } \\
\text { medio am- } \\
\text { biente. }\end{array}$ & $\begin{array}{l}\text { Promover } \\
\text { la práctica } \\
\text { de rotación } \\
\text { de cultivos } \\
\text { en parce- } \\
\text { las. }\end{array}$ & $\begin{array}{l}\text { Administrar nues- } \\
\text { tros medios de } \\
\text { vida sin influencia } \\
\text { de terceros. }\end{array}$ \\
\hline $\begin{array}{l}\text { 5- Capital } \\
\text { natural }\end{array}$ & $\begin{array}{l}\text { - Arboles de alto } \\
\text { valor comercial } \\
\text { (caoba, santa } \\
\text { maría, cedro, } \\
\text { etc.). } \\
\text { - Zona minera. } \\
\text { - Plantas medici- } \\
\text { nales. } \\
\text { - Áreas protegi- } \\
\text { das con respal- } \\
\text { do legal. } \\
\text { - Río Wawa. }\end{array}$ & $\begin{array}{l}\text { Marco nor- } \\
\text { mativo, } \\
\text { Resolución de } \\
\text { conflictos, La } \\
\text { institucionali- } \\
\text { dad del terri- } \\
\text { torio, proceso } \\
\text { de toma de } \\
\text { decisión. (ni- } \\
\text { vel alto). }\end{array}$ & $\begin{array}{l}\text { Existe una co- } \\
\text { misión guarda } \\
\text { bosques. }\end{array}$ & $\begin{array}{l}\text { Cuenta } \\
\text { con un } \\
\text { manual } \\
\text { de sanea- } \\
\text { miento. } \\
\text { Título de } \\
\text { propie- } \\
\text { dad. }\end{array}$ & $\begin{array}{l}\text { Conservar el } \\
\text { buen uso de } \\
\text { los medio } \\
\text { de vida, usar } \\
\text { el bosque } \\
\text { de manera } \\
\text { racional. } \\
\text { Buscar } \\
\text { proyectos } \\
\text { de refores- } \\
\text { tación, refo- } \\
\text { restar áreas } \\
\text { despaladas. } \\
\text { Delimitar } \\
\text { las áreas de } \\
\text { trabajo en el } \\
\text { bosque. }\end{array}$ & $\begin{array}{l}\text { Establecer } \\
\text { leyes den- } \\
\text { tro del te- } \\
\text { rritorio en } \\
\text { marcadas a } \\
\text { conservar } \\
\text { el uso del } \\
\text { bosque. } \\
\text { Frenar la } \\
\text { creación } \\
\text { de potreros } \\
\text { para gana- } \\
\text { do. } \\
\text { Promover } \\
\text { la práctica } \\
\text { de rotación } \\
\text { de cultivos } \\
\text { en parce- } \\
\text { las. }\end{array}$ & $\begin{array}{l}\text { Implementar uso } \\
\text { de productos } \\
\text { orgánicos. } \\
\text { Vender oxígeno a } \\
\text { otros países. } \\
\text { Darle uso racio- } \\
\text { nal a las reservas } \\
\text { mineras. }\end{array}$ \\
\hline
\end{tabular}




\begin{tabular}{|c|c|c|c|c|c|c|c|}
\hline \multirow{2}{*}{ Capitales } & \multirow{2}{*}{ Capitales de la comunidad } & \multirow{2}{*}{$\begin{array}{c}\text { Sistema de } \\
\text { gobernanza de } \\
\text { prioridad al capital }\end{array}$} & \multirow{2}{*}{ Oportunidades } & \multirow{2}{*}{ Fortaleza } & \multicolumn{3}{|c|}{ Línea de tiempo (Acciones) } \\
\hline & & & & & Corto (1-5años) & Mediano (6-10) & Largo (11-15) \\
\hline $\begin{array}{l}\text { 6- Capital } \\
\text { físico-cons- } \\
\text { truido }\end{array}$ & $\begin{array}{l}\text { - } \text { Cuatro iglesias. } \\
\text { - } 2 \text { escuelas. } \\
\text { - } 1 \text { centro de } \\
\text { salud. } \\
\text { - } 1 \text { casa comunal. } \\
\text { - } 2 \text { casas pastora- } \\
\text { les. } \\
\text { - } \quad \text { Una carretera } \\
\text { en buen esta- } \\
\text { do. }\end{array}$ & $\begin{array}{l}\text { Marco nor- } \\
\text { mativo, } \\
\text { resolución } \\
\text { de conflictos } \\
\text { internos. }\end{array}$ & $\begin{array}{l}\text { Oficina de } \\
\text { "Nación } \\
\text { Mayangna" } \\
\text { Contactos con el } \\
\text { gobierno regional } \\
\text { y consejo regio- } \\
\text { nal. }\end{array}$ & $\begin{array}{l}\text { El territo- } \\
\text { rio cuenta } \\
\text { con una } \\
\text { oficina } \\
\text { equipada } \\
\text { con equi- } \\
\text { pos tec- } \\
\text { nológicos: } \\
\text { computa- } \\
\text { dora, im- } \\
\text { presora, } \\
\text { GPS, radio } \\
\text { de comu- } \\
\text { nicación, } \\
\text { panel } \\
\text { solar. }\end{array}$ & $\begin{array}{l}\text { Vía de acce- } \\
\text { so terrestre. }\end{array}$ & $\begin{array}{l}\text { Crear } \\
\text { torres de } \\
\text { control de } \\
\text { incendios y } \\
\text { entrada de } \\
\text { colonos al } \\
\text { territorio. }\end{array}$ & $\begin{array}{l}\text { Construir torres } \\
\text { de control de } \\
\text { incendios y en- } \\
\text { trada de colonos } \\
\text { al territorio. }\end{array}$ \\
\hline $\begin{array}{l}\text { 7- Capital } \\
\text { financie- } \\
\text { ro-produc- } \\
\text { tivo }\end{array}$ & $\begin{array}{l}\text { - Ganados (bo- } \\
\text { vino, porcino, } \\
\text { equino). } \\
\text { - Parcelas de cul- } \\
\text { tivos (semillas) } \\
\text { - Recursos mine- } \\
\text { ros. } \\
\text { - Los recursos } \\
\text { acuáticos. } \\
\text { - Conocimientos } \\
\text { básicos de } \\
\text { elaboración de } \\
\text { botes. } \\
\text { - Programas de } \\
\text { gobierno. }\end{array}$ & $\begin{array}{l}\text { Marco nor- } \\
\text { mativo, re- } \\
\text { solución de } \\
\text { conflictos, } \\
\text { proceso de } \\
\text { toma de deci- } \\
\text { siones. }\end{array}$ & $\begin{array}{l}\text { Convenios con las } \\
\text { dos universidades } \\
\text { de la región. } \\
\text { Se cuenta con } \\
\text { asesoría técni- } \\
\text { ca de algunas } \\
\text { instituciones en } \\
\text { temas de interés } \\
\text { del territorio. }\end{array}$ & $\begin{array}{l}\text { Vía de } \\
\text { acceso } \\
\text { terrestre. }\end{array}$ & $\begin{array}{l}\text { Cuenta con } \\
\text { un manual } \\
\text { de sanea- } \\
\text { miento. } \\
\text { Título de } \\
\text { propiedad. }\end{array}$ & $\begin{array}{l}\text { Establecer } \\
\text { leyes den- } \\
\text { tro del te- } \\
\text { rritorio en } \\
\text { marcadas a } \\
\text { conservar } \\
\text { el uso del } \\
\text { bosque. } \\
\text { Promover } \\
\text { la práctica } \\
\text { de rotación } \\
\text { de cultivos } \\
\text { en parce- } \\
\text { las. }\end{array}$ & $\begin{array}{l}\text { Darle uso racio- } \\
\text { nal a las reservas } \\
\text { mineras. } \\
\text { Administrar nues- } \\
\text { tros medios de } \\
\text { vida sin influencia } \\
\text { de terceros. }\end{array}$ \\
\hline
\end{tabular}

\section{Conclusiones}

1. La comunidad de Awastingni cuenta con 7 capitales, entre los cuales se destaca el capital natural, como son: Arboles de alto valor comercial: Caoba (Swieteniamacrophylla), Santa maría (Calophyllum brasiliense), Cedro (CedrelaOdorata), etc), Zona minera, Plantas medicinales, Áreas protegidas con respaldo legal, Río Wawa. Y capital, que se ejerce una mayor presión debido a la intervención del ser humano.

2. Al mismo tiempo, existe un gran avance de la frontera agrícola provocado por la invasión de colonos dentro del territorio, ha venido a causar un desequilibrio y por consiguiente una mala influencia en 
el uso de los medios de vida, ya que se ha venido cambiando el uso del suelo de vocación forestal a las practicas pecuarias.

3. Uno de los grandes retos que tiene este territorio es el de tener la capacidad de defender lo que aún queda de los capitales del territorio ya que los mismos líderes territoriales y comunales junto con autoridades de gobierno y partidos políticos han vendido sus tierras.

4. El territorio indígena Amasau cuenta con cuatro sistemas de gobernanza (Marco normativo, institucionalidad del territorio, resolución de conflictos, proceso de toma de decisión). De los cuales el marco normativo tiene mayor influencia en todos los sectores del territorio ya que cada área está organizada (en estructura) de manera que se tenga un control sobre el uso, control y acceso a los medios de vida.

5. El territorio ha tenido en sus manos el poder de gobernar sus medios de vida ya que cuentan con instrumentos que les sirve como defensa ante colonos, sin embargo, no se ha podido dar un buen uso a esos instrumentos debido a la fragilidad y falta de liderazgo capaz de encaminar al territorio hacia un desarrollo.

6. Existe un alto grado de respeto hacia la mujer ya que son tomadas en cuenta, no solo como participantes para las asambleas, sino como tomadoras de decisiones en lo que respecta a los temas de mujer y en los temas generales del territorio.

7. El territorio Indígena Amasau aun cuenta con una considerada extensión de masa boscosa, por lo que ofrece una puerta para el pago por servicios ambientales y realizar gestiones de reducción de las emisiones causadas por la deforestación y la degradación de los bosques, conocido ahora como REDD+.

8. Los comunitarios del territorio Amasau son dueños de las tierras por lo que eso facilita a la negociación personal de tierras con colonos, creando de esta manera un camino hacia la destrucción del medio ambiente y los medios de vida.

9. Los comunitarios del territorio, poseen un gran conocimiento en temas de adaptación, prevención y mitigación ante el cambio climático por lo que están muy conscientes del impacto negativo que está causando dentro del territorio.

10. Este estudio servirá como un instrumento de guía para que, al pasar de los años, los habitantes del territorio Amasau puedan retomar sus acciones a seguir en el marco de la gobernanza de sus medios de vida, teniendo en cuenta que el cambio climático es una realidad a la cual se debe enfrentar. Por tanto, deberán de trabajar de prioridad la gobernabilidad endógena, la cual garantizara la gobernanza exógena.

\section{Agradecimiento}

Esta publicación obtuvo el financiamiento de: El Fondo de Asistencia Internacional de los Estudiantes y Académicos Noruegos (SAIH).

\section{Lista de referencias}

Convenio OIT 169. Convenio 169 de la Organización Internacional del Trabajo sobre pueblos indígenas y tribales.

Cunningham, M., Mairena D., \& Mairena, E. (2009). Guía sobre cambio climático y pueblos indígenas: un cuaderno de referencias. Managua, Nicaragua. p 17-18. 
Gonzalo (2013). Percepciones políticas y prácticas de participación como instrumento para la gobernanza de los territorios 2016; Universidad de los lagos, Santiago Chile. EURE.

Huanacuni F. (2010). Buen Vivir / Vivir Bien Filosofía, políticas, estrategias y experiencias regionales andinas. $\left(1^{a}\right.$ ed.) CAOI.

IPCC (Intergovernamental Panel onClimateChange). (2002). Impactos Regionales del cambio climático: Evaluación de la vulnerabilidad. Recuperado el 15 de abril de 2015, dehttp://www.ipcc.ch/pdf/technical-papers/climate-changes-biodiversity-sp.pdf.

Ley 28 (1987). Estatuto de Autonomía de las Dos Regiones de la Costa Atlántica de Nicaragua y su Reglamento.

Mairena, (2012). Cambo climático: medidas de adaptación en comunidades de las Regiones Autónomas de la Costa Caribe de Nicaragua. Editorial Arista. Managua, Nicaragua. p 8-24

Ramirez, Hernandez, Rivas, Padilla, Ete (2012). La perspectiva de género en los procesos de desarrollo comunitario y sostenible; CATIE; P: 19-20. Costa Rica.

Saavedra, C. (2007). Gestión comunitaria. (Documento en Línea) disponible:http://carlossaavedramartinez.blogspot.com/2007/07/gestioncomunitaria.html. (Consulta: 2015, Octubre 10). 